\title{
O Cinema e a Educação Bioética no Curso de Graduação em Medicina
}

\author{
Cinema and Bioethical Education in Medical \\ School
}

\author{
Pedro Henrique Netto Cezar \\ Andréia Patrícia Gomes ${ }^{I I}$ \\ Rodrigo Siqueira-Batista ${ }^{I I I}$
}

\section{PALAVRAS-CHAVE \\ - Educação Médica. \\ - Bioética. \\ - Cinema.}

\section{KEYWORDS}

- Medical Education.

- Bioethics.

- Cinema.
Artigo recebido em: 24/12/2008

Reencaminhado em: 29/09/2009

Reencaminhado em: 03/03/2010

Aprovado em: 04/08/2010

REVISTA BRASILEIRA DE EDUCAÇÃO MÉDICA
${ }^{I}$ Centro Universitário Serra dos Órgãos, Teresópolis, RJ, Brasil; Instituto Federal de Educação, Ciência e Tecnologia do Rio de Janeiro, Nilópolis, RJ Brasil.

"Universidade Federal de Viçosa, Viçosa, MG, Brasil.

III Universidade Federal de Viçosa, Viçosa, MG, Brasil;Universidade Federal do Rio de Janeiro, Rio de Janeiro, RJ,Brasil. 


\section{INTRODUÇÃO}

A insatisfação das pessoas em relação aos médicos vem se caracterizando como um importante problema na atualidade ${ }^{1,2}$. Entre os determinantes deste contexto estão, precisamente, os processos de ensino-aprendizagem em utilização na escola médica, pautados em currículos arcaicos, marcados pela dissociação teoria / prática, básico/clínico e pela visão biologicista do processo saúde-doença ${ }^{3,4}$. Esse modo de operar, baseado sobretudo em leituras (equivocadas?) do relatório Flexner, tem sua origem nos Estados Unidos no início do século 20 e se dissemina pelo mundo como a estratégia eficaz de formação do profissional médico, centrando o ensino no hospital, hipervalorizando a ciência biomédica e concorrendo para a fragmentação e a especialização precoce ${ }^{5}$.

Para minimizar esses problemas, o Ministério da Educação (MEC), desde a publicação de suas Diretrizes Curriculares Nacionais do Curso de Graduação em Medicina (DCN), de $2001^{6}$, vem privilegiando uma política educacional pautada na integralidade, a qual sustenta que o graduando deve estar envolvido em atividades ligadas à promoção, à prevenção, à reabilitação e à recuperação da saúde. Aposta-se que isto promova o desenvolvimento de uma postura humanística no discente, ao mesmo tempo em que o aproxima da sociedade. Desta maneira, o foco deixa de ser predominantemente conteudista ${ }^{7}$ para se centrar primeiramente no estudante destacando-se a aquisição de uma atitude crítica, que o torna capaz não somente de analisar a doença num contexto clínico, mas também de considerar todos os fatores sociais, psicológicos e ambientais que influenciam diretamente seu aparecimento - e, sobretudo, no paciente, entendido como um outro que necessita de cuidado, algo muito além de mera assistência.

A questão que se impõe com respeito à implantação das $\mathrm{DCN}$, para que estas se tornem vivas, diz respeito às ferramentas metodológicas que podem ser identificadas e postas em ação para prover o estudante das competências exigidas para o perfil do egresso pleiteado ${ }^{6}$ :

O curso de graduação em Medicina tem como perfil do formando egresso/profissional o médico, com formação generalista, humanista, crítica e reflexiva, capacitado a atuar, pautado em princípios éticos, no processo de saúde-doença em seus diferentes níveis de atenção, com ações de promoção, prevenção, recuperação e reabilitação à saúde, na perspectiva da integralidade da assistência, com senso de responsabilidade social e compromisso com a cidadania, como promotor da saúde integral do ser humano.
Neste âmbito, tem se destacado o uso de filmes para trabalhar conceitos relativos à formação do médico, especialmente aqueles atinentes ao campo da ética e da bioética, modalidade que vem sendo introduzida como recurso pedagógico ainda de forma discreta no curso superior, porém como uma competente ferramenta, que permite aos estudantes, por meio das narrativas apresentadas na tela, discutir assuntos de extrema relevância. Muitas vezes, os filmes provocam vivências carregadas de emoção, que podem despertar uma reflexão sobre a vida e a realidade, domínio particularmente fecundo das artes, conforme delimitado por Aristóteles em sua célebre Arte poética": "O terror e a compaixão podem nascer do espetáculo cênico, mas podem igualmente derivar do arranjo dos fatos, o que é preferível e mostra maior habilidade do poeta" (p. 54).

Ademais, o cinema permite que o estudante incorpore conceitos ao seu repertório cognitivo, desenvolvendo seu poder de análise crítica9:

Determinadas experiências culturais, associadas a uma certa maneira de ver filmes, acabam interagindo na produção de saberes, identidades, crenças e visões de mundo de um grande contingente de atores sociais. (Duarte ${ }^{10}$ 2006, p. 19)

Ao se assistir e procurar interpretar um filme, os conhecimentos adquiridos na educação formal agem de modo mais positivo em etapas posteriores do processo de significação, ou seja, após a construção do discurso sobre o que se viu e a internalização do que foi vivenciado.

$\mathrm{O}$ cinema pode ser inserido no contexto pedagógico da mídia-educação, representada pelas Técnicas de Informação e Comunicação (TIC), consistindo em uma moderna tecnologia de ensino-aprendizagem ${ }^{11}$. Além disso, ao adotar o cinema como recurso pedagógico, o aparelho formador incentiva a formação cultural do discente, estimulando a interdisciplinaridade na construção do conhecimento ao permitir uma ligação entre os diferentes aspectos socioeconômico-culturais em torno dos quais a sociedade se estrutura. Desde esta perspectiva ${ }^{12}$ : "O significado de um texto ou filme é o todo, amálgama desse conjunto de pequenas partes, em que cada uma não é suficiente para explicá-lo, porém todas são necessárias e cada uma só tem significado pleno em relação a todas as outras" (p. 48).

O professor que opta por utilizar o cinema deve ter o cuidado de escolher adequadamente o filme que vai utilizar, articulando-o aos itens curriculares que deseja abordar, de forma a manter a contextualização da atividade e sua consequente significação. É importante que o docente atue como facilitador 
da atividade, cuidando para que todos tenham seu espaço e se exercitem na escuta uns dos outros:

\begin{abstract}
A proposta de preparar os envolvidos para o diálogo e entendimento da imagem em movimento e seus diferentes pontos de vista é orientada pela concepção construtivista, segundo a qual a aprendizagem é concebida como um processo contínuo e dinâmico de acomodação e assimilação, em que crianças e adultos modificam suas estruturas cognitivas internas através de suas experiências pessoais, nas relações com o mundo. Os conhecimentos prévios, interesses, expectativas, motivações, necessidades, experiências e ritmos de aprendizagem serão considerados durante todo o processo. (Martins ${ }^{13}$ 2008, p. 860)
\end{abstract}

Com base nestes pressupostos, propõe-se, neste artigo, discutir possibilidades de uso do cinema para a educação bioética no âmbito dos cursos de graduação em Medicina.

\section{BIOÉTICA E FORMAÇÃO MÉDICA}

A relevância da bioética para a formação do médico está explicitada nas DCN, ao priorizar abordagens que permitam ao estudante o desenvolvimento de competências para a atenção/ cuidado à saúde ${ }^{6}$ :

Art. 4⿳⺈ A formação do médico tem por objetivo dotar o profissional dos conhecimentos requeridos para o exercício das seguintes competências e habilidades gerais:

I - Atenção à saúde: os profissionais de saúde, dentro de seu âmbito profissional, devem estar aptos a desenvolver ações de prevenção, promoção, proteção e reabilitação da saúde, tanto em nível individual quanto coletivo. Cada profissional deve assegurar que sua prática seja realizada de forma integrada e contínua com as demais instâncias do sistema de saúde, sendo capaz de pensar criticamente, de analisar os problemas da sociedade e de procurar soluções para os mesmos. Os profissionais devem realizar seus serviços dentro dos mais altos padrões de qualidade e dos princípios da ética/bioética, tendo em conta que a responsabilidade da atenção à saúde não se encerra com o ato técnico, mas, sim, com a resolução do problema de saúde, tanto em nível individual como coletivo. (p. 1)

A questão que se impõe, ato contínuo à leitura das DCN, diz respeito à "natureza" da bioética, campo do saber que, em sua formulação pelo oncologista Van Rensslaer Potter, em
1970, foi concebido como uma nova ética científica capaz de dar respostas à deterioração das relações homem-natureza e cujos objetivos principais seriam garantir a perpetuação da espécie humana e de sua qualidade de vida ${ }^{14}$. De outro modo, em 1971, Hellegers ${ }^{15}$, fundador do Kennedy Institute of Ethics, utilizou o termo para definir uma nova ética biomédica, uma extensão da ética médica. Embora possa ser entendido como um movimento típico das sociedades laicas e pluralistas contemporâneas da segunda metade do século 20, deve-se reconhecer sua inscrição na tradição da ética ocidental como uma das éticas aplicadas, como já identificava Warren Thomas Reich na introdução à segunda edição revista da Encyclopedia of Bioethics em $1995^{16}$

Ao longo destes 40 anos, a bioética adquiriu diferentes conformações teóricas ${ }^{17}$, ainda que não tenha deixado de se orientar para a discussão da moralidade das ações humanas ${ }^{18}$. Com efeito, ao considerar os atos humanos em termos morais, duas funções podem ser pensadas como inerentes à disciplina: (a) a descritiva e (b) a normativa, que permitem, respectivamente, explicitar os conflitos e propor a melhor forma de agir diante deles. Nesta perspectiva, a bioética se ocupa em analisar os argumentos morais relativos a determinadas práticas humanas que afetam a qualidade de vida e o bem-estar dos humanos - e dos demais seres ${ }^{19}$ - e em tomar decisões baseadas nas análises anteriores. Pode-se incluir, também, uma dimensão protetora, a partir da articulação das funções (a) e (b), como proposto por Schramm e Kottow ${ }^{20,21}$. Tal compreensão está em consonância com o apresentado na Declaração Universal sobre Bioética e Direitos Humanos ${ }^{22}$.

A abordagem destes conceitos nos currículos dos cursos médicos tem sido ainda problemática, como apontado por vários autores. Rego et al. ${ }^{23}$ discutem o fato de a educação bioética, enquanto formação moral, no âmbito da medicina, muitas vezes não ser suficiente para atender às necessidades dos profissionais de saúde. Para os autores, o Código de Ética, que deve existir em todas as profissões, contém normas para estabelecer critérios de etiqueta profissional — ou seja, sobre como agir em determinadas situações - , padronizando o comportamento corporativo a ser seguido pelos trabalhadores. Porém, o compromisso social implícito em tal regulamentação, na área da saúde, deve ser abordado pela bioética, levando o profissional a avaliar a pertinência de determinadas ações que podem ser danosas ao ser humano e a tomar as decisões apropriadas.

A partir desses pressupostos, a distribuição, a seleção de conceitos e a operacionalização para o enfoque de tais temas deverão ser orientadas, prioritariamente, para a utilização de metodologias que permitam que o estudante seja o centro do 
processo de aprendizagem, isto é, que ele seja ativo na construção de seu conhecimento ${ }^{7}$, tendo o professor como um orientador e não um ditador de regras e preceitos a seguir.

É possível empregar diferentes métodos para a educação bioética, capazes de propiciar a aquisição de novas possibilidades de reflexão para o estudante ${ }^{24-34}$. Merecem destaque, de acordo com Rego et al. ${ }^{35}$ :

- Discussão de casos - método apropriado para trabalhar o desenvolvimento da competência em ética ou bioética, pressupondo que os partícipes apliquem um conhecimento aprendido (em geral, princípios gerais morais ou técnicos) a um caso particular;

- Júri simulado - estratégia capaz de aferir a habilidade dos participantes em convencer uma audiência sobre sua posição em um debate público;

- Role-playing - empregado para que os participantes possam demonstrar como distintas pessoas atuam em diferentes papéis com diversas perspectivas e pontos de vista ("familiar", "profissional de saúde", "paciente" e outros); os papéis são representados - e não vividos - e, em geral, não proporcionam o surgimento de sentimentos autênticos;

- Discussão de dilemas morais / Método Konstanz - proposto por Lind ${ }^{24}$, realiza-se a partir da apresentação de um dilema e separação do grupo em pessoas a favor e contra a postura adotada; o facilitador da atividade precisa conhecer, suficientemente, aspectos do desenvolvimento moral para provocar desequilíbrios na argumentação dos participantes sem conduzir a resposta, atuando para que a discussão transcorra num ambiente de respeito mútuo; tem se mostrado uma forma muito eficiente para a construção da capacidade de se colocar num debate buscando compreender argumentos contrários aos próprios e reconhecer o valor de tais argumentos;

- Debates mediados pela arte - inclui discussão de livros (e demais textos literários), visita a museus e exposições, e outras atividades, capazes de evocar o debate bioético a partir de vivências artísticas;

- Apresentação de narrativas visuais - estão disponíveis distintas possibilidades, como os documentários (Quadro 1), os docudramas - híbridos entre gêneros, mesclando o estilo documentário e a representação ficcional realizada por atores ${ }^{32}$ — e os vídeos educativos, que se baseiam no reconhecimento do alto valor estético e pedagógico das imagens para o ensino de diferentes saberes, entre os quais a bioética;

- Discussão de filmes de cinema - em última análise, um subgrupo do item anterior; os filmes despertam e mobilizam sentimentos morais, podendo ser usados como casos a serem discutidos.
QuADRO 1

Tipos de documentários com possível utilização educacional

\begin{tabular}{|c|c|}
\hline Tipo de documentário & Comentários \\
\hline $\begin{array}{l}\text { Documentários de } \\
\text { divulgação científica }\end{array}$ & $\begin{array}{l}\text { Apresentam conceitos, teorias, métodos e } \\
\text { paradigmas científicos numa linguagem } \\
\text { simples e acessível, visando tanto o } \\
\text { público infantil quanto o público leigo }\end{array}$ \\
\hline $\begin{array}{l}\text { Documentários sobre } \\
\text { fenômenos naturais }\end{array}$ & $\begin{array}{l}\text { Procuram explicar a gama de } \\
\text { fenômenos ambientais coletivos e suas } \\
\text { consequências sociais e humanas }\end{array}$ \\
\hline $\begin{array}{l}\text { Documentários sobre } \\
\text { processos vitais }\end{array}$ & $\begin{array}{l}\text { Abordam questões relacionadas ao } \\
\text { ecossistema e ciclos da natureza, com } \\
\text { diferentes tipos de enfoques }\end{array}$ \\
\hline $\begin{array}{l}\text { Documentários sobre } \\
\text { temas e problemas } \\
\text { atuais }\end{array}$ & $\begin{array}{l}\text { Apresentam temas e problemas } \\
\text { atuais com enfoque jornalístico } \\
\text { (cultura, violência, política, cotidiano); } \\
\text { neste subtipo, há possibilidade de } \\
\text { interferências ideológicas e interesses } \\
\text { institucionais do grupo produtor do } \\
\text { documentário }\end{array}$ \\
\hline $\begin{array}{l}\text { Documentáros sobre } \\
\text { temas históricos }\end{array}$ & $\begin{array}{l}\text { Possuem duas naturezas: material } \\
\text { fílmico e iconográfico antigo - fruto de } \\
\text { pesquisa em acervos pessoais e públicos } \\
\text { —e depoimentos de protagonistas ou } \\
\text { especialistas no tema analisado }\end{array}$ \\
\hline $\begin{array}{l}\text { Documentários } \\
\text { antropológicos }\end{array}$ & $\begin{array}{l}\text { Expõem material visual acerca de temas } \\
\text { como subculturas jovens urbanas, } \\
\text { relações familiares, comportamento } \\
\text { e preferências sexuais, grupos } \\
\text { profissionais, confessionais, étnicos e } \\
\text { migrantes, fornecendo ao estudante uma } \\
\text { visão plural da sociedade }\end{array}$ \\
\hline
\end{tabular}

Fonte: Napolitano $\mathrm{M}^{30} \mathrm{e}$ Guilhem et al. ${ }^{31}$

O ideal, em termos de educação bioética, é utilizar múltiplos métodos, de modo a ampliar as possibilidades de fundamentação da tomada de decisão frente aos problemas e dilemas bioéticos. É preciso que o docente conheça as vantagens e limitações de cada método, como no caso do uso do cinema, comentado em maior detalhe a seguir.

\section{CINEMA COMO “FERRAMENTA": POSSIBILIDADES NA EDUCAÇÃO BIOÉTICA}

A necessidade de ampliar a discussão bioética no currículo médico se articula à ponderação sobre os métodos de ensino deste saber, cabendo destaque ao uso de filmes de cinema. Tal estratégia permite aos estudantes relacionar a realidade apresentada com a sua própria e rever alguns conceitos construídos ao longo dos anos, uma vez que o cinema cria um amplo espaço de debates, fazendo aflorar, em seus espectadores, reações inusitadas, que muito refletem as nuances de seu caráter ${ }^{33}$. 
O uso de filmes tem grande aplicabilidade como recurso pedagógico para a educação na área da saúde, tendo em vista a formação de profissionais de saúde engajados no cuidado ao paciente. Médicos, enfermeiros, psicólogos, fisioterapeutas e cirurgiões-dentistas devem ter acesso, ao longo do curso de graduação, aos conceitos de bioética, para que possam melhor lidar com os pacientes e, principalmente, ampliar suas possibilidades de reconhecê-los, de fato, como outros. Diversos filmes que tratam de questões relevantes - como processo saúde-doença, interação paciente-profissional de saúde, interseções homem-ambiente e relações (microfísicas) de poder (Quadro 2) - podem ser empregados para contemplar questões curriculares importantes, abrangendo o olhar ampliado sobre o paciente e não apenas o enfoque na doença que este apresenta. Tapajós ${ }^{36}$ salienta que o ensino das Humanidades aos profissionais de saúde permite a discussão de situações que concorrem para o adoecer, ao contrário de trabalhar apenas o conteúdo científico isolado, de forma fragmentada e descontextualizada da realidade. Através do cinema, este conhecimento científico vai ser adquirido no bojo do estabelecimento de relações com a situação apresentada ao estudante:

QUADRO 2

Sugestões de filmes para utilização em atividades dirigidas à bioética

\begin{tabular}{|c|c|c|c|c|}
\hline Filme & Questão a ser trabalhada & Direção & Ano & Sinopse \\
\hline $\begin{array}{l}\text { As Invasões } \\
\text { Bárbaras }\end{array}$ & $\begin{array}{c}\text { Bioética e o fim } \\
\text { da vida }\end{array}$ & Denys Arcand & 2003 & $\begin{array}{l}\text { O professor de História Rémy Girard, recém-diagnosticado com uma } \\
\text { doença grave, recebe apoio da família e dos amigos para lidar com seu } \\
\text { processo de morrer, objetivando o alcance de um final de vida mais } \\
\text { digno por meio de diferentes modalidades terapêuticas, incluindo } \\
\text { o uso de drogas ilícitas. Diferentes diálogos e situações permitem } \\
\text { debates a respeito da eutanásia, além de propiciarem uma reflexão } \\
\text { sobre as políticas públicas de saúde. }\end{array}$ \\
\hline $\begin{array}{l}\text { Cobaias (Miss } \\
\text { Ever's boys) }\end{array}$ & $\begin{array}{l}\text { Bioética na } \\
\text { experimentação em } \\
\text { animais, incluídos os } \\
\text { seres humanos }\end{array}$ & Joseph Sargent & 1997 & $\begin{array}{l}\text { Baseado em fatos reais, o filme mostra a implantação e o } \\
\text { desenvolvimento de um estudo sobre a sífilis, realizado no sul dos } \\
\text { Estados Unidos a partir de 1932. Durante anos, centenas de homens } \\
\text { negros recebem “acompanhamento" médico, sendo-lhes negado } \\
\text { o tratamento para a enfermidade - mesmo após o advento da } \\
\text { penicilina, na década de } 1940 \text { - e a informação sobre sua utilização } \\
\text { como cobaias humanas. A película é significativa para a discussão } \\
\text { sobre a ética em pesquisa envolvendo seres humanos. }\end{array}$ \\
\hline $\begin{array}{c}\text { Frankenstein, } \\
\text { de Mary Shelley }\end{array}$ & $\begin{array}{l}\text { Bioética na } \\
\text { experimentação em } \\
\text { animais, incluídos os } \\
\text { seres humanos }\end{array}$ & $\begin{array}{l}\text { Kenneth } \\
\text { Branagh }\end{array}$ & 1994 & $\begin{array}{l}\text { Baseado no clássico romance Frankenstein ou o Moderno Prometeu, } \\
\text { de Mary Shelley, retrata a história do estudante de Medicina Victor } \\
\text { Frankenstein, que constrói um ser inominado em seu laboratório, } \\
\text { utilizando porções de cadáveres. O filme pode ser empregado, com } \\
\text { exxito, para discussões em torno dos limites da ciência e, inclusive, } \\
\text { para se colocar em questão a própria condição humana. }\end{array}$ \\
\hline $\begin{array}{c}\text { Gattaca - } \\
\text { Experiência } \\
\text { Genética }\end{array}$ & $\begin{array}{l}\text { Bioética e o início da } \\
\text { vida / Bioética na } \\
\text { experimentação em } \\
\text { animais, incluídos os } \\
\text { seres humanos }\end{array}$ & Andrew Niccol & 1997 & $\begin{array}{l}\text { A história se passa em um tempo futuro, em que as crianças são } \\
\text { geradas geneticamente. Neste contexto, Vincent, concebido de } \\
\text { forma "natural", com um DNA que mostra grande chance de } \\
\text { desenvolvimento de cardiopatia e de morte precoce (antes dos } 30 \\
\text { anos), luta contra seus próprios genes em busca do sonho de se tornar } \\
\text { astronauta. Bioética do início da vida, experimentação em seres } \\
\text { humanos, eugenia e determinismo genético estão entre os assuntos } \\
\text { que podem ser discutidos a partir do filme. }\end{array}$ \\
\hline $\begin{array}{l}\text { O Dia Depois de } \\
\text { Amanhã }\end{array}$ & Bioética e ecologia & $\begin{array}{l}\text { Roland } \\
\text { Emmerich }\end{array}$ & 2004 & $\begin{array}{l}\text { O filme descreve uma catástrofe meteorológica prevista pelo } \\
\text { climatologista Jack Hall, autor de uma teoria sobre o aquecimento } \\
\text { global e a alteração dos fluxos das correntes marítimas. Película } \\
\text { interessante para desencadear debates sobre a bioética e a ecologia. }\end{array}$ \\
\hline
\end{tabular}




\begin{tabular}{|c|c|c|c|c|}
\hline Filme & Questão a ser trabalhada & Direção & Ano & Sinopse \\
\hline O Informante & $\begin{array}{l}\text { Bioética, ciência e } \\
\text { política }\end{array}$ & Michael Mann & 2000 & $\begin{array}{l}\text { Baseada em fatos reais, a história diz respeito ao episódio em que } \\
\text { a indústria estadunidense de tabaco é colocada em xeque após a } \\
\text { denúncia de um cientista, que rompe a claúsula de confidencialidade } \\
\text { do seu contrato de trabalho, expondo à mídia o uso incorreto e } \\
\text { antiético de dados científicos e os malefícios causados pelo uso do } \\
\text { cigarro. O filme pode ser empregado para a discussão dos aspectos } \\
\text { éticos das profissões, motivando particularmente o debate sobre o } \\
\text { papel da ciência no mundo contemporâneo. }\end{array}$ \\
\hline O Jardineiro Fiel & $\begin{array}{l}\text { Bioética na } \\
\text { experimentação } \\
\text { em animais, } \\
\text { incluídos os seres } \\
\text { humanos / Bioética, } \\
\text { ciência e política }\end{array}$ & $\begin{array}{l}\text { Fernando } \\
\text { Meirelles }\end{array}$ & 2006 & $\begin{array}{l}\text { Neste filme observa-se o descaso que alguns representantes da } \\
\text { indústria farmacêutica têm em relação à vida humana ao testarem } \\
\text { novos medicamentos sob o pretexto da distribuição gratuita de } \\
\text { fármacos contra a AIDS, sem o conhecimento da população. A película } \\
\text { permite a discussão dos aspectos éticos da ciência e a reflexão sobre } \\
\text { os determinantes sociais, políticos e econômicos que fazem com que } \\
\text { os países africanos permaneçam em situação de pobreza e de crise na } \\
\text { saúde pública. }\end{array}$ \\
\hline $\begin{array}{l}\text { O Ovo da } \\
\text { Serpente }\end{array}$ & $\begin{array}{l}\text { Bioética na } \\
\text { experimentação em } \\
\text { animais, incluídos } \\
\text { os seres humanos } \\
\text { / Bioética, ciência e } \\
\text { política }\end{array}$ & $\begin{array}{l}\text { Ingmar } \\
\text { Bergman }\end{array}$ & 1977 & $\begin{array}{l}\text { A história se passa na Alemanha (Berlim) devastada pela Primeira } \\
\text { Guerra Mundial, na qual começa a brotar o germe do nazismo. Um } \\
\text { jovem desempregado, que consegue trabalho com um cientista, } \\
\text { acaba por desvendar uma nefasta rede de observação e manipulação } \\
\text { de pessoas. Os aspectos bioéticos das pesquisas envolvendo seres } \\
\text { humanos e os aspectos ético-políticos do nazismo podem ser tratados } \\
\text { a partir deste filme. }\end{array}$ \\
\hline $\begin{array}{c}\text { O Segredo de Vera } \\
\text { Drake }\end{array}$ & $\begin{array}{c}\text { Bioética e o início da } \\
\text { vida }\end{array}$ & Mike Leigh & 2004 & $\begin{array}{l}\text { Vera Drake é uma simpática e carinhosa senhora que trabalha como } \\
\text { empregada doméstica, mas que, nas horas vagas, auxilia mulheres na } \\
\text { prática do aborto, movida pelo anseio de ajudá-las. O filme apresenta } \\
\text { as tensões entre os aspectos éticos e legais do aborto, sendo bastante } \\
\text { interessante para os debates sobre a bioética do início da vida. }\end{array}$ \\
\hline Os Doze Macacos & $\begin{array}{c}\text { Bioética na } \\
\text { experimentação em } \\
\text { animais, incluídos os } \\
\text { seres humanos }\end{array}$ & Terry Gilliam & 1995 & $\begin{array}{l}\text { O filme mostra um futuro no qual a humanidade está condenada a } \\
\text { viver de forma insalubre no interior da terra em consequência de um } \\
\text { ato bioterrorista, décadas antes. O protagonista, um presidiário, torna- } \\
\text { se "voluntário" para fazer uma viagem de retorno no tempo, a fim } \\
\text { de tentar descobrir os responsáveis pelo ataque. Permite a discussão } \\
\text { sobre o uso experimental de seres vivos e o uso descontrolado da } \\
\text { natureza e dos recursos científicos em prol de objetivos escusos. }\end{array}$ \\
\hline $\begin{array}{l}\text { Uma Verdade } \\
\text { Inconveniente }\end{array}$ & $\begin{array}{c}\text { Bioética e ecologia } \\
\text { / Bioética, ciência e } \\
\text { política }\end{array}$ & $\begin{array}{c}\text { Davis } \\
\text { Guggenheim }\end{array}$ & 2007 & $\begin{array}{l}\text { O filme aborda de maneira contextualizada os aspectos científicos } \\
\text { atuais associados à questão do aquecimento global e das mudanças } \\
\text { climáticas. Discute também a associação existente entre os problemas } \\
\text { ambientais e questões sociais, políticas e econômicas mundiais. } \\
\text { Pode ser utilizado para fomentar debates sobre bioética e ecologia, e } \\
\text { relações entre ciência e política. }\end{array}$ \\
\hline
\end{tabular}

Fonte: Siqueira-Batista et al. ${ }^{39}$ (p. 309-317).

Os recursos lúdicos tornam possível a identificação do aluno com um ou mais personagens das histórias, gerando diálogos sobre o seu cotidiano, suas práticas, os riscos a que está sujeito em seu ambiente, promovendo com isso uma reflexão sobre a saúde e sua vida, num contexto de troca com os colegas e o professor. Daí pode emergir a construção de novos conceitos científicos sobre promoção de saúde e cuidado em saúde, assim como práticas a serem evitadas e soluções coletivas a serem implementadas a partir de movimentos comunitários e de iniciativas da própria escola. (Pimenta et $\mathrm{al}^{38}, 2006$, p. 91)
Os filmes devem ser trabalhados em consonância com os temas a abordar e não incluídos apenas como forma de entretenimento puro e sem compromisso. Ao escolher um filme para discutir com a turma, é importante que o professor esteja ciente do tipo de abordagem pedagógica que adotará em sua discussão e que conheça as várias formas possíveis de exploração do conteúdo exposto, tornando a atividade rica, prazerosa e útil para a construção do conhecimento: "A relevância da articulação entre cinema e educação se dá pela formação para a sensibilidade, para desenvolver as capacidades cognoscitivas de alunos e educadores" ${ }^{\prime \prime 7}$ (p. 111). 
Um aspecto que merece atenção diz respeito às relações entre a extensão dos filmes e a duração das aulas. Nas situações em que há compatibilidade, ou seja, o filme "cabe" no período da aula, parece ser ideal a apresentação de toda a película, tendo em vista a indissociabilidade entre seu valor artístico e o potencial para a educação. Quando o filme é mais longo do que o tempo previsto para o encontro professor-aluno, tem-se a opção de expor partes da narrativa visual, desde que estas sejam suficientes para integrar adequadamente o processo ensino-aprendizagem da temática em pauta. Também pode se solicitar que o estudante assista ao filme num momento extra-aula, o que tem como inconveniente as dificuldades de acesso à película - por exemplo, o discente pode não o encontrar e o fato de ocorrer o "esvaziamento" do caráter educativo, já que a exposição ocorre fora dos "muros" da escola.

O uso do cinema para discutir questões bioéticas no curso de Medicina tem se mostrado um recurso de grande aceitação pelos estudantes, visto ser uma atividade lúdica e que promove o debate, pois o aprendiz transpõe para a sua realidade os fatos vivenciados na tela, passando a considerar o contexto socioeconômico, político e cultural que permeia as situações do cotidiano ${ }^{39,40}$. Dessa forma, o cinema permite a incorporação de diferentes saberes ao repertório cognitivo do indivíduo, sempre pautada pela ressignificação que este faz de seu conhecimento prévio. Marías ${ }^{41}$ considera que o cinema aumenta as possibilidades das vivências que em cada pessoa se encontram reduzidas a um pequeno repertório de experiências reais. Os filmes, com frequência, mostram situações bem próximas do cotidiano do espectador, fazendo-o rever posturas, considerar novas hipóteses ao analisar a situação do outro, aspectos que, na medicina, permitem ao estudante, muitas vezes, abandonar algumas ideias preconcebidas, que dificultam o manejo de situações com marcante interseção moral. Marías ainda enfatiza o uso do cinema como um recurso de educação em atitudes humanas, levando em conta virtudes e valores inerentes a cada pessoa:

O cinema promove a oportunidade e o espaço para um diálogo amplo, multitemático, de questões que ocupam e preocupam, de fato, o estudante e que nem sempre encontram forma acadêmica para serem abordadas. $\mathrm{O}$ educador surge como um facilitador do diálogo entre os alunos, expondo temas relativos ao ser humano e à vida. $\left(\right.$ Blasco $^{42}, 2005$, p.125)

A educação aparece como um lugar de negociação de conflitos de interesses e conflitos de valores ${ }^{43}$, o qual diz respeito aos elementos físicos (aprendizagens corporais), sociais (comportamentos com os outros) e mentais (valores morais), estendendo-se por um tempo longo, uma vez que a educação humana atinge, muitas vezes, um quarto do tempo de vida esperado. Devem ser respeitadas as concepções prévias dos alunos, como o conhecimento adquirido em família e em suas relações com o ambiente, o qual pode se articular ao conhecimento científico por meio de um contínuo processo de construção. Trazendo essas premissas para a educação médica, percebe-se a potência do cinema como catalisador para o acesso aos conceitos bioéticos, com a finalidade de criar no estudante a consciência de seu futuro papel de cuidador.

\section{CONSIDERAÇÕES FINAIS}

A formação médica atual tem as DCN como decisivo mote, reconhecendo-se que o estudante deve, desde cedo, ser levado a desenvolver uma postura ética e humanista, a fim de no futuro estar apto a exercer uma relação médico-paciente pautada no respeito ao outro. Para isto, são incentivadas metodologias de ensino voltadas não apenas para a aquisição de conhecimentos técnicos, mas que também proporcionem a interação ensino-cuidado, tornando o aluno consciente da realidade que enfrentará no futuro.

Dentre essas metodologias, destaca-se o uso do cinema para fomentar debates em diferentes áreas do saber ${ }^{44,45}$, incluindo a bioética. Nesta perspectiva, trata-se de uma atividade extremamente interessante porque permite a discussão e análise de situações próximas da realidade, gerando subsídios para o estudante analisar decisões morais a serem tomadas frente a certos eventos. A formação bioética é extremamente necessária para todos os profissionais da saúde, ressaltando-se a importância da solidariedade, do acolhimento, do reconhecimento da alteridade e da compaixão na construção das relações com o outro, aspectos essenciais ao cuidado em saúde.

\section{REFERENCIAS}

1. Bitencourt AGV, Neves NMBC, Neves FBCS, Brasil ISPS, Santos LCS. Análise do erro médico em processos ético-profissionais: implicações na educação médica. Rev Bras Educ Med. 2007; 31(3):223-8.

2. Minossi JG. Prevenção de conflitos médico-legais no exercício da medicina. Rev Col Bras Cir. 2009;36(1):90-5.

3. Feuerwerker L. Além do discurso de mudança na educação médica. SP: Hucitec; 2002.

4. Silva Santos S. A integração do ciclo básico com o profissional no curso de graduação em medicina: uma resistência exemplar. Rio de Janeiro: Papel \& Virtual; 2005.

5. Oliveira GS, Koifman L. Integralidade do currículo de medicina: inovar/ transformar, um desafio para o processo de 
formação. In: Marins JJN, Rego S, Lampert JB, Araujo JGC Educação Médica em Transformação. São Paulo: Hucitec; 2004. p.143-64.

6. Brasil. Senado. Resolução n. 4 CNE/CES, de 2001. Institui Diretrizes Curriculares Nacionais do Curso de Graduação em Medicina. Diário Oficial da União. Brasília, 9 de novembro de 2001. Seção 1, pg. 38.

7. Mitre SM, Siqueira-Batista R, Girardi-de-Mendonça JM, Morais-Pinto NM, Meirelles CAB, Pinto-Porto, Cláudia C, Moreira T, Hoffmann LMA. Metodologias ativas de ensino-aprendizagem na formação profissional em saúde: debates atuais. Ciênc Saúde Colet. 2008;13(supl. 2):2133-44.

8. Aristóteles. Arte poética. São Paulo: Martin Claret; 2005.

9. Blasco P. Medicina da família e cinema: recursos humanísticos na educação médica. São Paulo: Ed. Casa do Psicólogo; 2002.

10. Duarte R. Cinema e educação. $2^{\underline{a}}$ ed. Belo Horizonte: Ed. Autêntica; 2006.

11. Belloni ML. O que é mídia: educação. São Paulo: Autores Associados; 2001.

12. Almeida MJ. Imagens e sons: a nova cultura oral. São Paulo: Cortez; 2001.

13. Martins AF, Costa MA. O cinema como mediador na educação da cultura visual. $17^{\circ}$ Encontro Nacional da Associação Nacional de Pesquisadores em Artes Plásticas. Panoramo de Pesquisas em Artes Visuais. 19 a 23 de agosto de 2008-Florianópolis.

14. Potter VR. Bioethics, science of survival. Biol Med. 1970; 14:173-53.

15. Goldim JR. Bioética e ética na ciência. [online]. [acesso em fev. 2010]. Disponível em: http://www.ufrgs.br/bioetica/ bioetica.htm.

16. Reich WT. Encyclopedia of bioethics. [S.1]: Mac Millan Library; 1995.

17. Ferrer JJ, Alvarez JC. Para fundamentar a bioética. São Paulo: Loyola; 2005

18. Kottow M. Introdución a la bioética. Santiago: Universitária; 1995.

19. Siqueira-Batista R, Gomes AP, Rôças G. Ética para todos os seres e ecologia profunda: um preliminar diálogo com relevância para a saúde pública. Cad Saúde Coletiva. 2009;17:529-44.

20. Kottow M. Bioética de proteção: considerações sobre o contexto latino-americano. In: Schramm FR. Bioética: riscos e proteção. Rio de Janeiro: Ed. Fiocruz; 2005. p. 29-44.

21. Schramm FR. Bioética da proteção: justificativas e finalidades. Iatrós - Ensaios de Filosofia, Saúde Cultura. 2005;1:121-30.
22. UNESCO. Declaração Universal em Bioética e Direitos Humanos [online]. Tradução Ana Tapajós e Mauro Machado do Prado. [acesso em 22 set. 2009]. Brasília: UNESCO; 2005. Disponívelemwww.bioetica.catedraunesco.unb.br/htm/X\%20-\%20htm/documentos/declaracaojulho2006.pdf.

23. Rego S, Palácios M, Schramm FR. Ensino da bioética nos cursos de graduação em saúde. In: Marins JJN, Rego S, Lampert JB, Araújo JGC. Educação médica em transformação. São Paulo: Hucitec; 2004. p.165-85.

24. Lind G K. Method of Dilemma Discussion [online]. [acesso em 9 set. 2009]. Disponível em http:/ / www.uni-konstanz. de/ag-moral/

25. Siqueira-Batista R, Santos SS, Osterne EMC, Cardoso APF, Caramel JM. Ética e formação médica II: o cinema e o teatro no debate bioético sobre o fim da vida. Rev Digital Educ Permanente Saúde. 2004;1:62.

26. Tapajós R. A comunicação de notícias ruins e a pragmática da comunicação humana: o uso do cinema em atividades de ensino/aprendizagem na educação médica. Interface Comun Saúde Educ. 2007;11(21):165-72.

27. Nunes ED, Hennington EA, Barros NF, Montagner MA. O ensino das ciências sociais nas escolas médicas: revisão de experiências. Ciênc Saúde Colet. 2003;8(1):209-25.

28. Ribeiro JS. Antropologia visual, práticas antigas e novas perspectivas de investigação. Rev. Antropol. 2005;48(2): 613-48.

29. Farné R. Iconologia didattica. Bologna: Zanichelli; 2004.

30. Napolitano M. Como usar o cinema na sala de aula. São Paulo: Contexto; 2006.

31. Guilhem D, Diniz D, Zicker F. Pelas Lentes do Cinema: bioética e ética em pesquisa. Brasília: Ed. Unb, Letras Livres; 2007. 180 p.

32. Fuenzalida V. O docudrama televisivo. Matrizes 2008; 2(1):159-2.

33. Carvalho AF, Moraes MS. A importância da tecnologia na sala de aula: a construção de um vídeo educativo sobre o meio ambiente na cidade de Aracaju. In: Anais do II seminário de educação, comunicação, inclusão e interculturalidade. Sergipe, 12 a 14 de agosto, 2009.

34. Girão LC. Produzindo audiovisual na escola: processos de produção de vídeos educativos [online]. [acesso em $23 \mathrm{fev}$. 2010]. Disponível em: http:// WWW.tvebrasil..com.br// salto/boletins2002/tedh/tedhtxt4a.htm

35. Rego S, Gomes AP, Siqueira-Batista R. Bioética e humanização como temas transversais na formação médica. Rev Bras Educ Med. 2008;32:482-91.

36. Tapajós R. A introdução das artes nos currículos médicos. Interface Comum Saúde Educ. 2002;6(10):27-36. 
37. Pinto FM, Pereira LG. A experiência de ver filmes na formação inicial de professores de educação física. Pensar a Prática. 2005;8(1):101-15.

38. Pimenta DN, Leandro AMS, Schall VT. Experiências de desenvolvimento e avaliação de materiais educativos sobre saúde: abordagens sócio-históricas e contribuições da antropologia visual. In: Monteiro S, Vargas E. Educação, Comunicação e Tecnologia Educacional. Rio de Janeiro: Ed. Fiocruz; 2006. p.87-112.

39. Siqueira-Batista R, Gomes AP, Rôças G, Leite SQM, Siqueira-Batista R. O cinema na formação bioética de professores de ciências. Anais do Encontro Nacional de Ensino de Ciências da Saúde e do Ambiente. Niterói: UNIPLI, 2008, p. 309-317.

40. Foucault MA. Pintura Fotogênica. In: Ditos e Escritos. Estética: Literatura e Pintura, Música e Cinema. Rio de Janeiro: Forense Universitária; 2001. p.346- 55.

41. Marías J. La educación sentimental. Madrid: Alianza Editorial; 1992.

42. Blasco PG, Gallian DMC, Poncoletta AFT, Moreto G. Cinema para o estudante de medicina: um recurso afetivo/efetivo na educação médica. Rev Bras Educ Med. 2005;29(2):119-28.

43. Gonnett J. Educação e mídias. São Paulo: Ed. Loyola; 2004.
44. Alves Ferreira R, De Andrade TS, Rôças G, Helayël-Neto JA, Siqueira-Batista R. Cinema e ensino de física.: XVIII Simpósio Nacional de Ensino de Física, 2009, Vitória. Anais do XVIII Simpósio Nacional de Ensino de Física. São Paulo: Sociedade Brasileira de Física, 2009. v. 1. p. 1-8.

45. Archanjo LR, Fraiz IC. O cinema como recurso humanístico na formação profissional. RUBS 2006;2(2):43-8.

\section{CONTRIBUIÇÃO DOS AUTORES}

Pedro Henrique Netto Cezar contribuiu na revisão bibliográfica e redação. Andréia Patrícia Gomes contribuiu na revisão bilbiográfica e Rodrigo Siqueira-Batista contribuiu na revisão bibliográfica e supervisão final do texto.

\section{CONFLITO DE INTERESSES}

Declarou não haver.

\section{ENDEREÇO PARA CORRESPONDÊNCIA}

Rodrigo Siqueira-Batista

Departamento de Medicina e Enfermagem — UFV

Av. Peter Henry Rolfs, s/n

Campus Universitário - Viçosa

CEP 36570-000 - MG

E-mail: rsiqueirabatista@yahoo.com.br 